\title{
Fragmentation mechanism of product ions from protonated proline-containing tripeptides in electrospray ionization mass spectrometry
}

\author{
YOU ZhuShuang ${ }^{1}$, WEN YongJun ${ }^{2}$, JIANG KeZhi $^{1,3}$ \& PAN YuanJiang ${ }^{1 *}$ \\ ${ }^{1}$ Department of Chemistry, Zhejiang University, Hangzhou 310027, China; \\ ${ }^{2}$ Chengdu Capgemini Biomedical Technology Company, Ltd., Chengdu 611330, China; \\ ${ }^{3}$ Key Laboratory of Organosilicon Chemistry and Material Technology, Hangzhou Normal University, Hangzhou 310012, China
}

Received December 16, 2011; accepted January 31, 2012

\begin{abstract}
The dissociation chemistry of primary fragment ions from the protonated proline-containing tripeptides glycylprolylglycine, prolylglycylglycine, and prolylprolylglycine was investigated by electrospray ionization multi-stage mass spectrometry. Calculations showed the $a_{2}$ ions generated from $b_{2}$ ions were cyclic, which is energetically more favorable than the linear form. The prolyl residue in the structure affected the energy hypersurface of the dissociation reaction from the $b_{2}$ ion to the $a_{2}$ ion. In the fragmentation of $\mathrm{a}_{2}$ ions, the iminium-imine complex corresponding to loss of $\mathrm{CO}$ from the $\mathrm{a}_{2}$ ion was suggested to be an ion-neutral complex (INC). The $\mathrm{a}_{1}$ ion was generated from direct separation of this INC, and the internal iminium ion, which was absent in PGG, was generated from another INC that was formed from the first INC via proton-bridged complex-mediated intramolecular proton transfer. Although these intermediates are unstable, their existence is supported by experiments and density functional theory calculations.
\end{abstract}

proline, cyclic $a_{2}$, ion-neutral complex, proton-bridged complex, intramolecular proton transfer, internal iminium ion, theoretical calculation

Citation: You Z S, Wen Y J, Jiang K Z, et al. Fragmentation mechanism of product ions from protonated proline-containing tripeptides in electrospray ionization mass spectrometry. Chin Sci Bull, 2012, 57: 2051-2061, doi: 10.1007/s11434-012-5117-z

Determination of amino acid sequences in peptides and proteins by mass spectrometry (MS) [1-4] is of considerable practical importance. Soft ionization techniques, such as electrospray ionization (ESI) [4-7] and matrix-assisted laser desorption/ionization (MALDI) [8,9], are used to produce intact peptide ions in the gas phase. The target peptide ion can be selected for fragmentation to provide sufficient structural information by tandem MS (MS/MS) and multistage $\mathrm{MS}\left(\mathrm{MS}^{n}\right)$ techniques. Combined with theoretical calculation methods, the primary fragmentation pathways and ionic structures of protonated peptides can be well established [10-15]. Peptide precursor ions under typical lowenergy, collision-induced dissociation (CID) conditions

*Corresponding author (email: panyuanjiang@ zju.edu.cn) fragment along amide bond backbones forming structurally informative sequence ions, including $\mathrm{b}_{n}$ and $\mathrm{y}_{n}$ ions containing $\mathrm{N}$ - and C-termini, respectively. The $\mathrm{b}_{n}$ and $\mathrm{y}_{n}$ ions formed on the primary peptide sequence can further fragment to form lower b ions, a ions, internal fragments, and internal immonium ions. Competition among these pathways is one of the main factors that determine the $\mathrm{MS}^{n}$ spectra of protonated peptides. Iminium ions $\left(\mathrm{RCH}=\mathrm{NH}_{2}^{+}\right)$are frequently observed at low mass/charge $(\mathrm{m} / \mathrm{z})$ ratios. These ions are good indicators of the particular amino acids present in a peptide sequence. For example, the ion at $\mathrm{m} / \mathrm{z} 70$ is a good indicator of the presence of proline if it is abundant in a peptide and no arginine is present [16,17]. Previous studies [18-23] have mainly focused on these initial fragmentation reactions rather than the subsequent fragmentation reactions 
leading to the final observed fragment ions. Currently, the dissociation mechanisms are not well understood, even for peptides that contain relatively "simple residues". $\mathrm{RCH}=\mathrm{NH}_{2}^{+}$ can be generated as $\mathrm{a}_{1}$ or an internal iminium ion.

Siu and co-workers [24-26] reported that iminium ions $\left(\mathrm{RCH}=\mathrm{NH}_{2}^{+}\right)$generation from $\mathrm{a}_{2}$ ions proceeds via an iminium-imine complex. This intermediate is called a protonbridged complex (PBC), which is a special type of ion-neutral complex (INC). INCs [27-32] are prominent in gas-phase unimolecular ionic reactions [33-39], and consist of an ionic fragment and a neutral molecule bind together through electrostatic attraction instead of a covalent bond. Before their final separation, various interesting chemical reactions occur in these temporary systems, including hydride transfer [35], charge transfer [37] and transacylation reactions [38,39], which do not occur between the same two components when connected by a covalent bond. In a PBC, two incipient neutrals are attached to a common proton, and the PBC often represents the transition state for the interconversion of INCs [28,39-41]. According to the literature on PBCs (Figure 1), proton transfer between INCs should be governed by the proton affinities (PAs) of the related molecules. When B has a substantially greater PA than A (by $\geqslant 12 \mathrm{kcal} \mathrm{mol}^{-1}$ ), the proton transfer from INC_A to PBC is essentially irreversible [29]. Intramolecular proton transfer from the first INC is thought to yield the second INC via PBC, and then the two INCs dissociate to $\mathrm{a}_{1}$ and the internal $\mathrm{RCH}=\mathrm{NH}_{2}^{+}$.

In this research, the tripeptides glycylprolylglycine (GPG), prolylglycylglycine (PGG), and prolylprolylglycine (PPG) were studied. Proline is unique DNA-encoding $\alpha$-amino acid because it has a secondary $\alpha$-amino group. Its cyclic pyrrolidine ring imposes rigid constraints on $\mathrm{N}-\mathrm{C}^{\alpha}$ rotation. Prolines play an important role in protein folding, which is necessary for the formation of the three-dimensional structures of physiologically active proteins (e.g., HIV-1 capsid protein [42]). Addition of proline can induce inactivation, for example, insertion of a proline at critical locations in amylin severely inhibits amyloid formation [43]. The biological functions of prolines are of considerable interest to researchers.

The presence of proline residues is important in MS studies of peptides and proteins. Because of their importance in the conformations of small peptides, proline residues may have a considerable influence on fragmentation patterns in MS/MS. With many protonated proline-containing peptides, the position of the proline residue has a major effect on the type of fragmentation that occurs. For example, when the prolyl residue is located at the C-terminal of a tripeptide, only the products of cleavage at the $\mathrm{C}$-terminal can be

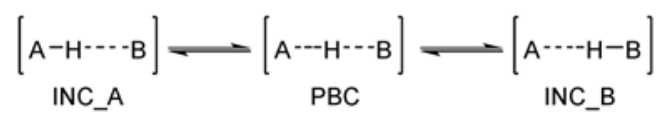

Figure 1 Interconversion of a pair of INCs via PBC. observed [11]. By contrast, when the prolyl residue is located centrally, both $b_{2}$ and $y_{2}$ ions are typically formed competitively [11]. In addition, these proline-directed processes are sometimes the only dissociation pathways observed for large proteins [44]. This proline effect is attributed to high gas-phase basicity or proton affinity of proline $[11,45]$.

Considering the importance of proline to peptides, we are interested in subsequent fragmentation reactions of protonated proline-containing peptides. The purpose of the present study was to probe the dissociation pathways of primary fragment ions from the aforementioned protonated proline-containing tripeptides by positive ESI combined with multi-stage MS. Density functional theory (DFT) calculations were performed to support the proposed fragmentation pathways.

\section{Methods}

(i) MS. Collision-induced dissociation experiments were performed using a Varian 500-MS (Palto Alto, CA) ion trap MS operated in positive ion mode and equipped with an ESI source. Data were acquired using the Varian MS Workstation. Samples were dissolved in methanol containing $0.1 \%$ formic acid at a concentration of approximately $0.1 \mu \mathrm{g} \mathrm{mL} L^{-1}$, and infused into the source chamber at $6 \mu \mathrm{L} \mathrm{min}^{-1}$. The parameters were set as follows: spray chamber temperature, $50^{\circ} \mathrm{C}$; needle voltage, $5000 \mathrm{~V}$; spray shield voltage, $600 \mathrm{~V}$; capillary voltage, $75 \mathrm{~V}$; RF loading, $85 \%$; scan mode, standard; drying gas temperature, $250^{\circ} \mathrm{C}$. Nitrogen was used as the drying gas at a pressure of $15 \mathrm{psi}$ and the nebulizing gas at a pressure of $35 \mathrm{psi}\left(1 \mathrm{psi}=6.895 \times 10^{5} \mathrm{~Pa}\right)$. Helium was used as the collision gas.

(ii) Theoretical calculations. All theoretical calculations were performed by density functional theory (DFT) at the B3LYP level with the 6-31G++(d,p) basis set in Gaussian 03 [46]. Previous studies have established that DFT calculations at the B3LYP level with the 6-31G++(d,p) basis set are satisfactory for molecules, such as protonated peptides, in which hydrogen bonds are ubiquitous [10-12,15,24-26, 47-51]. Hydrogen bonds are important in many structural details of protonated peptides and their fragmentation products, but are relatively weak. The candidate structures of the reactants, products, intermediates and transition states were optimized by calculating the force constants, while no symmetry constrains were imposed in the optimizations. The reaction pathways were traced forward and backward by the intrinsic reaction coordinate (IRC) method. All optimized structures (Table S1) were subjected to vibrational frequency analysis, shown in the reaction profiles by Gauss View software (version 3.09) to give higher quality images of these structures (red for oxygen and blue for nitrogen). All relative free energies $\left(\Delta G_{298}^{\circ}\right)$ are given in $\mathrm{kcal} \mathrm{mol}^{-1}$, and the lengths of the chemical bonds are given in $\AA$ (Table S2). 
To obtain theoretical relative proton affinities for the final fragments, both the neutral and protonated forms were computed, and the proton affinities were approximated from relative enthalpies $\left(\Delta H_{0}^{\circ}\right)$ (Table $\left.\mathrm{S} 3\right)$.

\section{Results and discussion}

For all the compounds studied, the protonated tripeptides were produced under positive ion ESI conditions. In the $\mathrm{MS}^{n}$ experiments, the product ion spectra of the precursor ion were obtained under the conditions described in the experimental section (Figures 2 and 3). All the protonated tripeptides tended to generate the relevant sequence ions (abundant $\mathrm{b}_{2}, \mathrm{a}_{2}$, and $\mathrm{a}_{1}$ ions) mainly by charge-directed reactions [52-54] upon activation under low-energy collision conditions. However, the position of the proline residue in the peptide affected the type of fragmentation that occurred [11]. The present study primarily focused on the formation and fragmentation of the $a_{2}$ ions. Theoretical computations were performed to support the proposed mechanisms and show the possible existence of some transition states and intermediates involved.

\subsection{Structures of the $a_{2}$ ions}

In previous studies, protonation of the nitrogen in the oxazolone ring [55-57] of the $b_{2}$ ion was believed weaken the carbonylic $\mathrm{C}-\mathrm{O}$ bond. Elimination of $\mathrm{CO}$ occurred through a concerted pathway $[51,56,57]$ involving the rupture of two covalent bonds of the cyclic $b_{2}$ ion and formation of the linear $a_{2}$ ion [53]. However, Siu and co-workers [24-26] proved by infrared multiple-photon dissociation spectroscopy and DFT calculations that linear $\mathrm{a}_{2}$ ions can be further stabilized by intramolecular nucleophilic attack of the $\mathrm{N}$ terminal amino nitrogen on the carbon of the iminium moiety. This forms a cyclic structure, such as an $\mathrm{N}_{1}$-protonated 4imidazolidinone for the $\mathrm{a}_{2}$ ion derived from triglycine. The
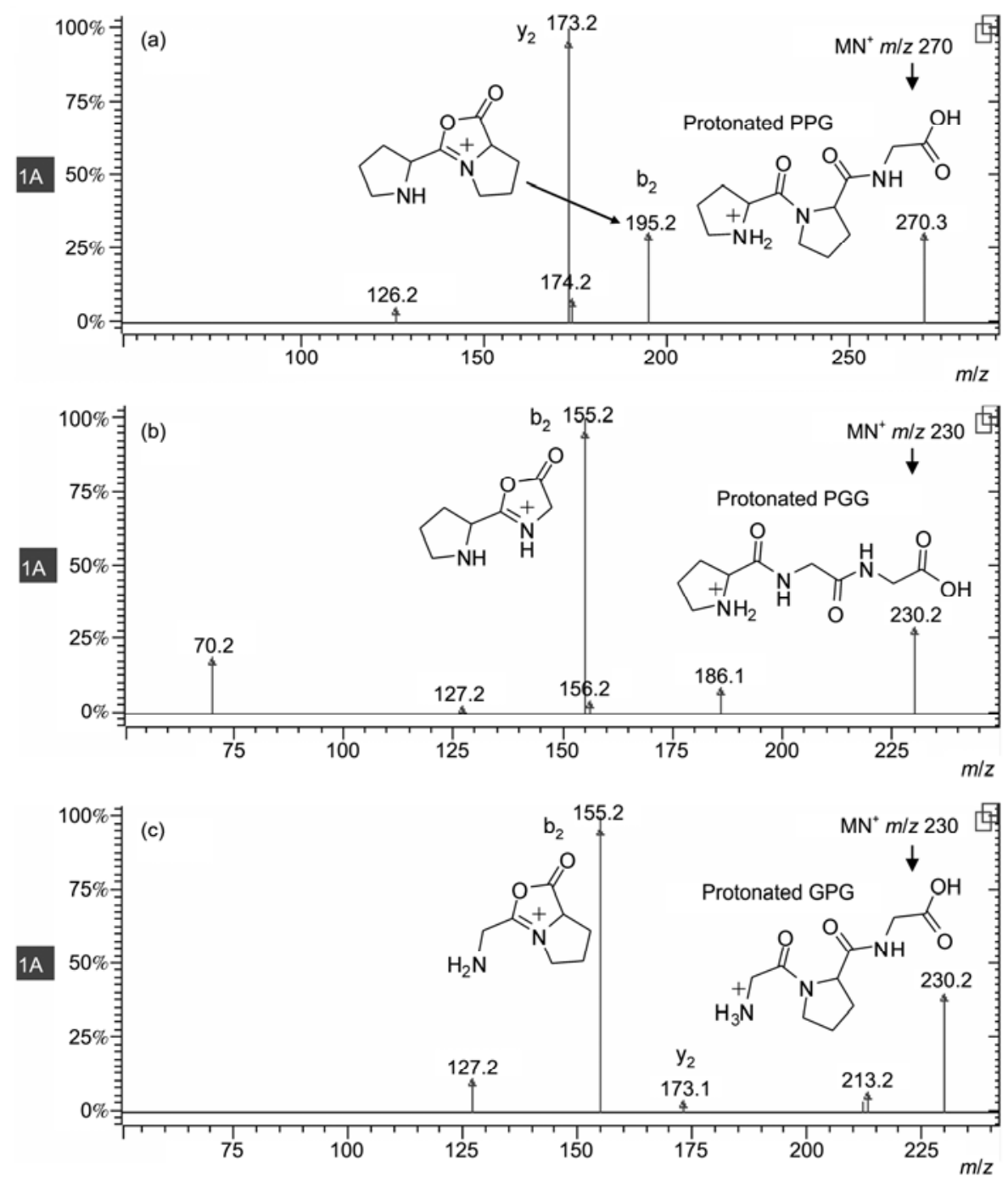

Figure 2 CID mass spectra of the $[\mathrm{M}+\mathrm{H}]^{+}$ions of PPG (a), PGG (b), GPG (c). 

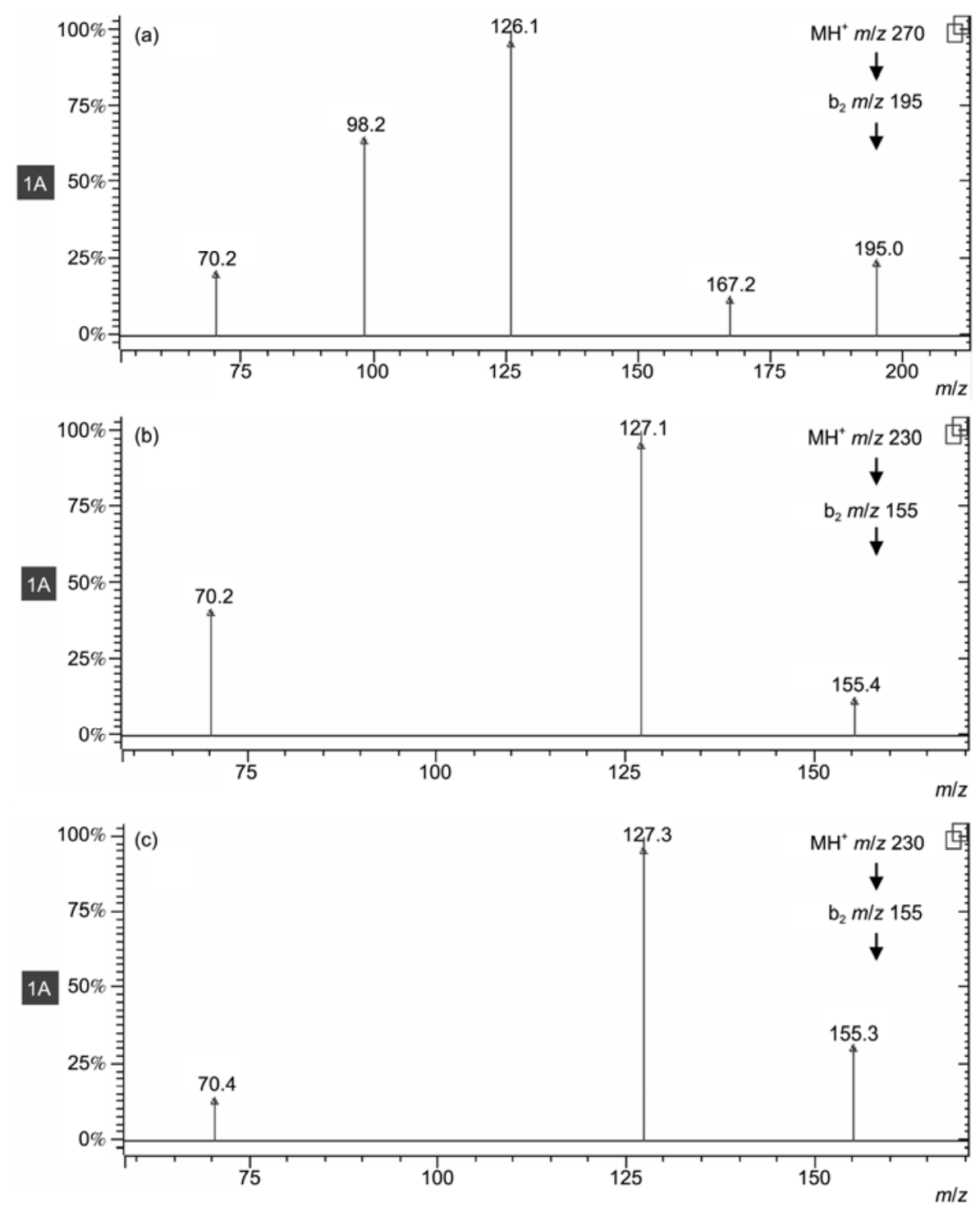

Figure 3 CID mass spectra of the $b_{2}$ ions from protonated PPG (a), PGG (b), GPG (c).

tripeptides studied herein all contain one or two proline residues. To assess whether the cyclic structures of the $a_{2}$ ions derived from proline-containing tripeptides are energetically favorable, the reaction profiles for the dissociation of $b_{2}$ from protonated PPG, PGG, and GPG to $a_{2}$ ions are illustrated in Figure 4.

The energy profiles of protonated PPG, PGG, and GPG were qualitatively similar to that from GGG [23], but differed quantitatively. The calculation results agree with those in the literatures, with the cyclic forms $\left(\mathrm{a}_{2}\right.$ '') more energetically favorable than the linear forms $\left(\mathrm{a}_{2}{ }^{\prime}\right)$ by $9.61,19.24$, and $1.32 \mathrm{kcal} \mathrm{mol}^{-1}$ for PPG, PGG, and GPG, respectively. Furthermore, the energy barriers $\left(\mathrm{TS}_{2}\right)$ to this isomerization process were only $4.25,8.94$, and $7.21 \mathrm{kcal} \mathrm{mol}^{-1}$ for PPG, PGG, and GPG, respectively. These results indicate that the isomerization processes are not difficult to overcome and the cyclic forms $\left(\mathrm{a}_{2}\right.$ '") are much more stable than the linear forms $\left(a_{2}{ }^{\prime}\right)$. Notably, the formal positive charge center is transferred from the nitrogen of the second amide residue to the nitrogen of the first amide residue (Figure 5). This is the main cause of the distinct energy difference between the two forms of the $a_{2}$ ion.

In PPG and GPG, the formal positive charge centers of the $a_{2}$ ' ions are located on the second prolyl residue, and the inductive effect of the pyrrolidine ring in this prolyl residue confers considerable charge stabilization on the $\mathrm{H}-\mathrm{N}^{+}$group, which results in a rather dramatic decrease in the energy. By contrast, the $\mathrm{a}_{2}$ ' ion from PGG is relatively higher in energy because of the absence of the second prolyl residue and the minimal influence on the $\mathrm{H}-\mathrm{N}^{+}$group from the pyrrolidine ring of the N-terminal prolyl residue. This is also why the energy hypersurface of PGG is much higher than that of PPG and GPG. Table 1 compares the $\Delta G_{298}^{\circ}$ values of the minima and transition-state structures.

However, the $\mathrm{a}_{2}$ ", ion of PPG is a notable exception, with an energy difference to the $\mathrm{a}_{2}$ ' ion of $19.24 \mathrm{kcal} \mathrm{mol}^{-1}$. This 

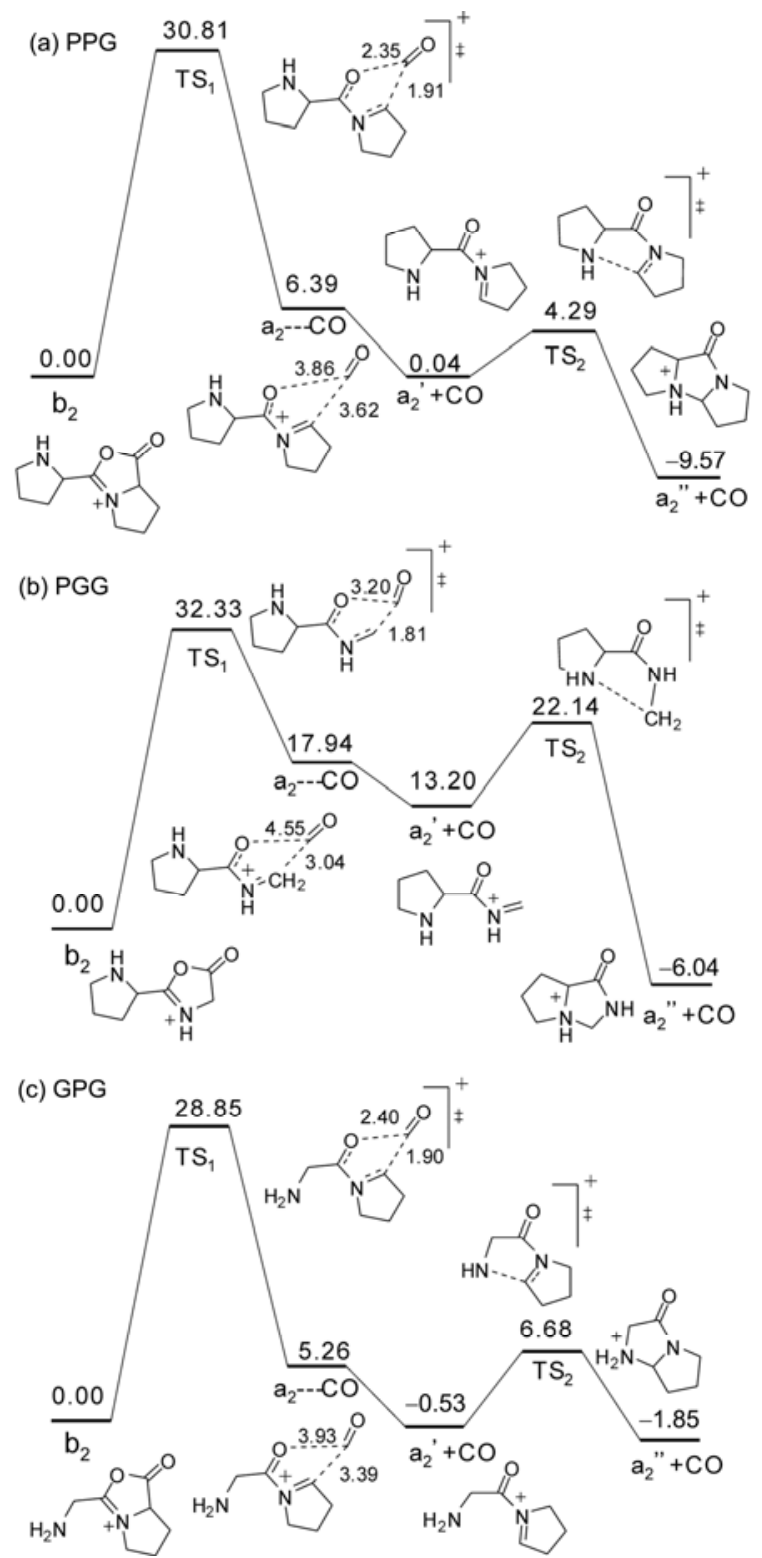

Figure 4 Reaction profile for dissociation of the $b_{2}$ to $a_{2}$ ions from protonated PPG (a), PGG (b), GPG (c). (a) PPG

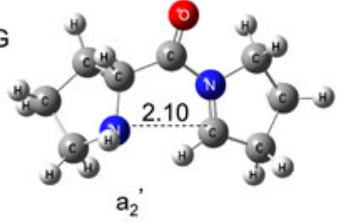

$0.04 \mathrm{kcal} \mathrm{mol}^{-1}$

(b) PGG

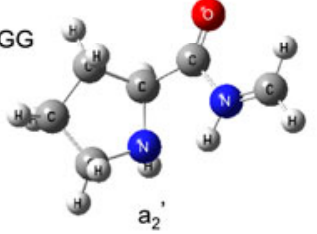

$13.20 \mathrm{kcal} \mathrm{mol}^{-1}$

(c) GPG

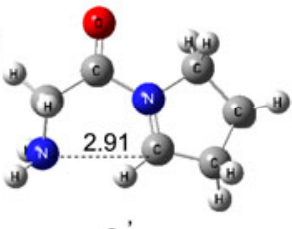

$a_{2}$

$-0.53 \mathrm{kcal} \mathrm{mol}^{-1}$

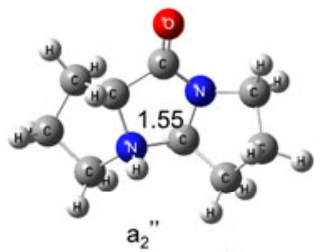

$9.57 \mathrm{kcal} \mathrm{mol}^{-1}$

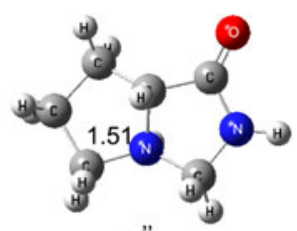

$a_{2} "$

$-6.04 \mathrm{kcal} \mathrm{mol}^{-1}$

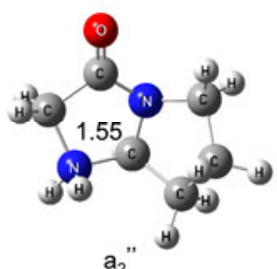

$-1.85 \mathrm{kcal} \mathrm{mol}^{-1}$
Figure 5 Optimized structures of the two forms of the $a_{2}$ ions (linear form: $a_{2}$ '; cyclic form: $a_{2}$ '") from protonated PPG (a), PGG (b) and GPG (c).

occurs because in the cyclization that forms $\mathrm{a}_{2}$ ", the formal positive charge center is transferred to the nitrogen of the first N-terminal prolyl residue, which places the formal positive charge center in the pyrrolidine ring. For the same reason, the energy difference between $\mathrm{a}_{2}$ "' and $\mathrm{a}_{2}$ ' of PPG is also distinct $\left(9.61 \mathrm{kcal} \mathrm{mol}^{-1}\right)$, but smaller than that of PGG. As for GPG, the energy difference is only $1.32 \mathrm{kcal} \mathrm{mol}^{-1}$, because the formal positive charge center is transferred to the first glycyl residue, and the influence of the pyrrolidine ring is lost. Therefore, the proline in the peptide affects the energy hypersurface of the reaction, and this effect is much stronger than that from alanine [25].

Table 1 Relative free energies $\left(\Delta G_{298}^{\circ}\right)$ for protonated GPG-, PGG-, PPG-derived ions and transition states $\left(\mathrm{kcal} \mathrm{mol}^{-1}\right)$

\begin{tabular}{|c|c|c|c|c|}
\hline & PPG & PGG & GPG & $N$-benzyl GPG \\
\hline $\mathrm{b}_{2}$ & 0.00 & 0.00 & 0.00 & $\mathrm{NA}^{\text {a) }}$ \\
\hline $\mathrm{TS}_{1}$ & 30.81 & 32.33 & 28.85 & $\mathrm{NA}^{\text {a) }}$ \\
\hline $\mathrm{a}_{2}{ }^{\prime}+\mathrm{CO}$ & 0.04 & 13.20 & -0.53 & 9.41 \\
\hline $\mathrm{TS}_{2}+\mathrm{CO}$ & 4.29 & 22.14 & 6.68 & 14.00 \\
\hline $\mathrm{a}_{2} "+\mathrm{CO}$ & -9.57 & -6.04 & -1.85 & 0.00 \\
\hline $\mathrm{TS}_{3}+\mathrm{CO}$ & 17.05 & 28.52 & 25.67 & 28.48 \\
\hline INC_A $+2 \mathrm{CO}$ & -20.61 & -8.61 & $\mathrm{NA}^{\mathrm{a})}$ & -4.16 \\
\hline PBC_TS+2CO & -21.74 & $\mathrm{NA}^{\mathrm{a})}$ & $\mathrm{NA}^{\mathrm{a})}$ & -4.73 \\
\hline INC_B+2CO & -20.61 & $\mathrm{NA}^{\mathrm{a})}$ & -9.64 & -4.91 \\
\hline
\end{tabular}



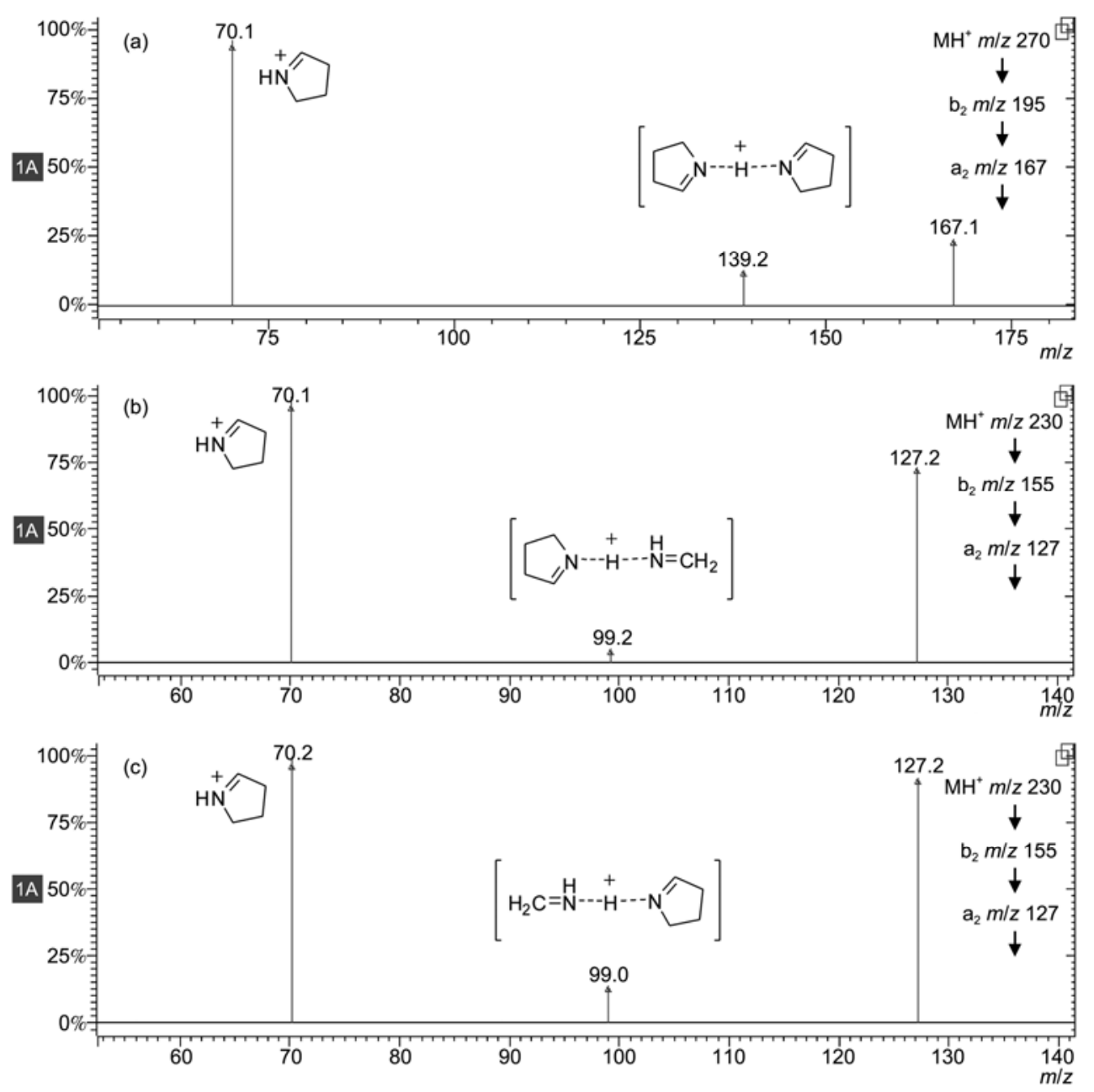

Figure 6 CID mass spectra of the $\mathrm{a}_{2}$ ions from protonated PPG (a), PGG (b) and GPG (c).

\subsection{Fragmentation of the $\mathrm{a}_{2}$ ion}

Figure 6 shows the product-ion spectra of the $\mathrm{a}_{2}$ ions from protonated PPG, PGG, and GPG. Generally, all the $\mathrm{a}_{2}$ ions provided similar fragmentation in the collision-induced dissociation MS experiments, yielding an abundant protonated molecule at $\mathrm{m} / \mathrm{z}, 70$. The other product ions $(\mathrm{m} / \mathrm{z} 99$ and $\mathrm{m} / \mathrm{z}$ 139) generated from the precursor $\mathrm{a}_{2}$ ions by the loss of $\mathrm{CO}$ were minor but noteworthy, for they are considered to be important gas-phase unimolecular ionic reaction intermediates, INCs, which are rarely seen in the production spectra.

The fragmentation of $\mathrm{a}_{2}$ ions to $\mathrm{a}_{1}$ and internal $\mathrm{RCH}=$ $\mathrm{NH}_{2}^{+}$proceeded via the aforementioned INC. However, to date, the dissociation chemistry of the INC to the internal $\mathrm{RCH}=\mathrm{NH}_{2}^{+}$has not been investigated in detail. We propose that the subsequent proton transfer between the ionic and neutral partners within the INC results in the PBC, and then isomerizes it to another INC. This hypothesis may account for the sufficiently long lifetime of this proton-bridged dimer under low-energy conditions for the proton transfers between the two fragments in the dimer. The two INCs split to $\mathrm{a}_{1}$ ions and internal $\mathrm{RCH}=\mathrm{NH}_{2}^{+}$. To describe the energy requirements of the reactions quantitatively, the mechanisms are shown in Figure 7, and the reaction profiles for the proposed mechanisms that fit the experimental data are shown in Figure 8.

For PPG (Figure 8(a)), the collisional activation of $\mathrm{a}_{2}$," resulted in breaking of the middle ring and formation of $\mathrm{a}_{2}$ '. Then, the simultaneous lengthening of the $\mathrm{C}-\mathrm{C}$ and $\mathrm{C}-\mathrm{N}$ bonds adjacent to the carbonyl group in $\mathrm{a}_{2}$ ' resulted in $\mathrm{TS}_{3}$. This step was critical in the dissociation, and $\mathrm{TS}_{3}$ was only $26.62 \mathrm{kcal} \mathrm{mol}^{-1}$ higher in energy than $\mathrm{a}_{2}$ ". On the product side of the $\mathrm{TS}_{3}$, there was an adduct between an INC and $\mathrm{CO}$. Once the weakly bound $\mathrm{CO}$ was repelled, an INC (INC_A) formed, in which the formal positive charge center was located on the imine of the first prolyl residue. Stabilized by $\mathrm{N}_{1}^{+}-\mathrm{H} \cdots \mathrm{N}_{2}$, the $\mathrm{H}-\mathrm{N}_{2}$ hydrogen bond between the ion and the neutral partner was at $1.58 \AA$, INC_A was 11.04 kcal mol ${ }^{-1}$ lower in energy than $\mathrm{a}_{2}$ ". Dissociation of INC_A led to formation of the $\mathrm{a}_{1}$ ion and neutral cyclic $\mathrm{RCH}=\mathrm{NH}$. A proton transfer reaction via PBC_TS can lead to INC_B, the minimum on the product side of PBC_TS is determined by an intrinsic reaction coordinate calculation, for which there is proton located at the imine of the second prolyl 
(a)<smiles>CC(=O)N1CCCC1C(=O)[N+]12CCCC1CC2</smiles>
CO<smiles>C1=NCCC1</smiles>
INC_A $m / z 139$

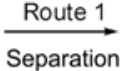

Separation

Route 2 Proton transfer<smiles>C[C@H](C1CCCC1)N1CCCC1</smiles>

PBC_TS m/z 139

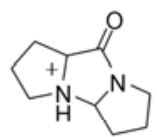

$a_{2} m / z 167$ (b) PGG

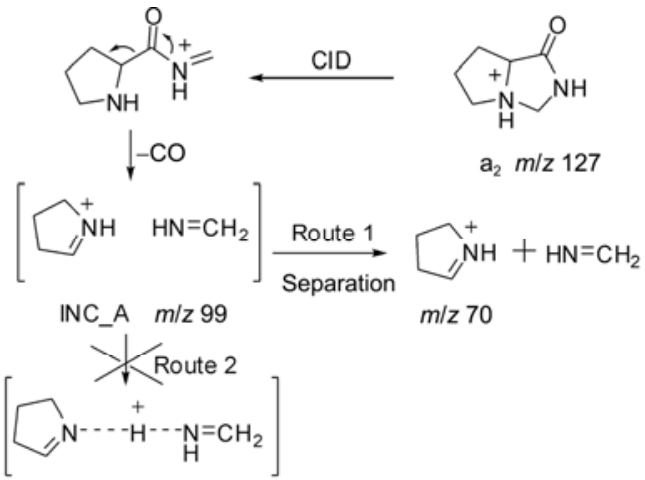

INC_B $\quad m / z 139$

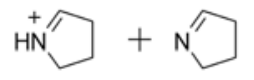

$\mathrm{m} / \mathrm{z} 70$

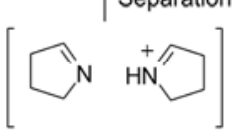

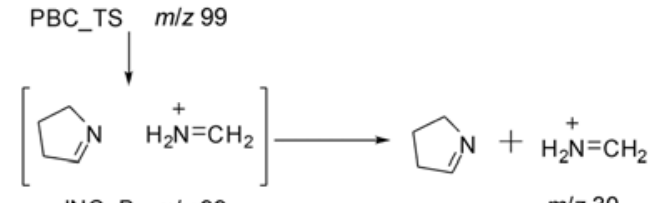

INC_B $\quad m / z 99$

$m / z 30$ (d)

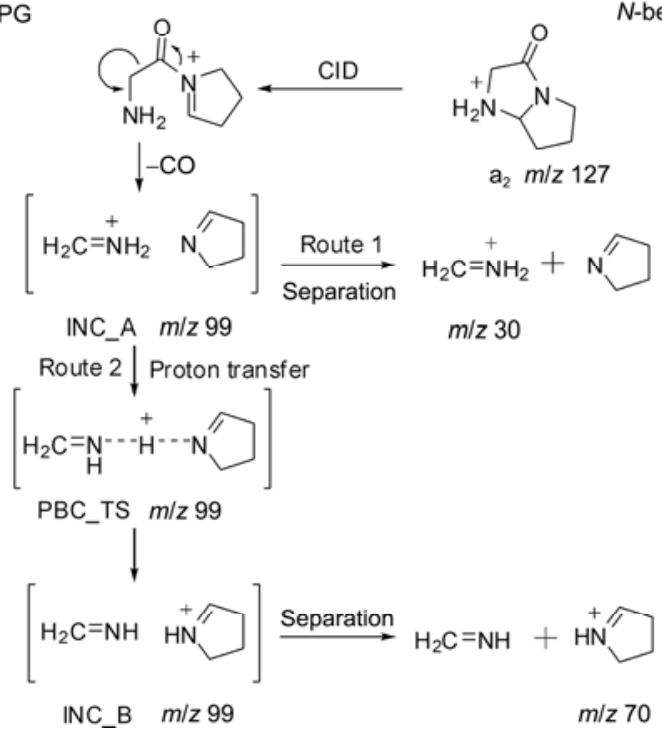

-benzyl GPG

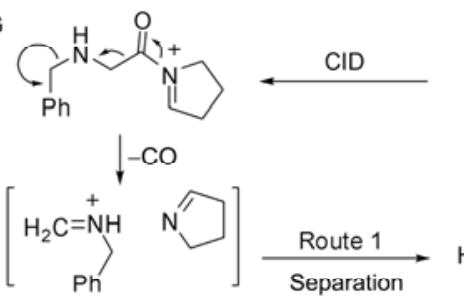

$$
\text { INC_A m/z } 189
$$

Route 2 $\mid$ Proton transfer

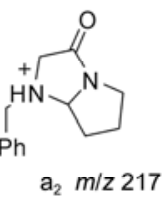

$a_{2} \quad m / z 217$

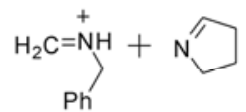

$\mathrm{m} / \mathrm{z} 120$

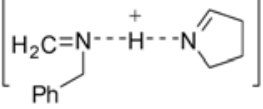

PBC_TS, m/z 189

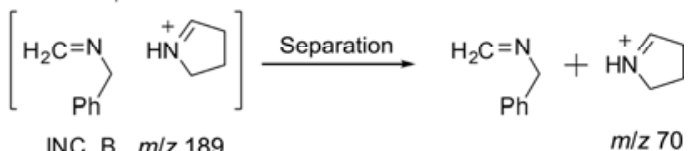

Figure 7 Proposed fragmentation mechanisms of the $\mathrm{a}_{2}$ ions from protonated PPG (a), PGG (b), GPG (c) and $N$-benzyl GPG (d).

residue. In the PPG energy hypersurface, PBC_TS was slightly lower in corrected zero-point energy (ZPE) than both INC_A and INC_B, which indicates that efficient proton transfer occurs and that INC_B can form easily after the preceding complex INC_A. These three important protonbridged dimer isomers are schematically presented in Figure 9(a)-(c). It was obvious that the $\mathrm{N}_{1}-\mathrm{H}-\mathrm{N}_{2}$ hydrogen bond lengths between the two neutral partners of PBC_TS were both at $1.29 \AA$, which meant that PBC_TS for PPG was symmetric because of the same two neutral partners, which were from the first and second prolyl residues. For the same reason, the two INCs were identical both in structure and energy. Dissociation of INC_B led to formation of the internal cyclic $\mathrm{RCH}=\mathrm{NH}_{2}^{+}$, which was indistinguishable from the $a_{1}$ ion because they shared the same fragment ion at $m / z 70$.

The intramolecular proton transfer reaction can be observed in the spectrum only when the first two residues are different. Nevertheless, no internal proton transfer occurred in PGG, and the dissociation of the $\mathrm{a}_{2}$ ions provided only the $a_{1}$ ion. The original proton was on the nitrogen of the first prolyl residue, so the proton was on the imine of the first prolyl residue in INC_A. The hydrogen bonds between cyclic $\mathrm{RCH}=\mathrm{NH}_{2}^{+}$and neutral $\mathrm{CH}_{2}=\mathrm{NH}$ from the second glycyl residue were $1.68 \AA$ (Figure 9(d)). The subsequent proton transfer to form INC_B is a difficult process. This is because the PA of the imine of the first prolyl residue is $16.65 \mathrm{kcal} \mathrm{mol}^{-1}$ higher (in terms of relative enthalpies $\left(\Delta H_{0}^{\circ}\right)$, Table S3) than that of the imine of the second glycyl residue in PGG. Consequently, no protonated methanimine $(\mathrm{m} / \mathrm{z}, 30)$ was produced (Figure 7(b)).

Theoretically, as in GPG, given that the imine of the second prolyl residue has a greater PA than the imine of the 

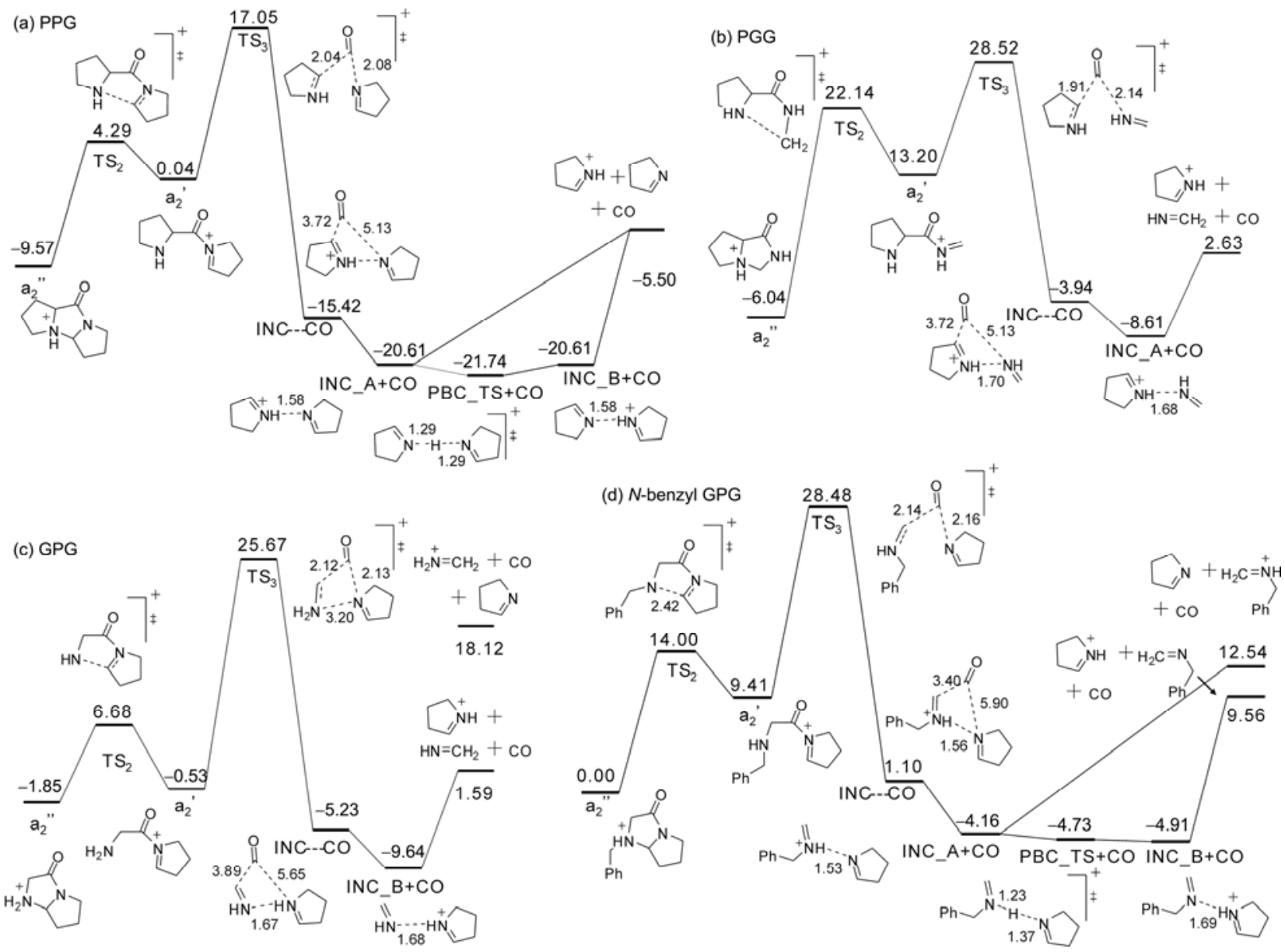

Figure 8 Reaction profile for dissociation of the $\mathrm{a}_{2}$ to $\mathrm{a}_{1}$ ions from protonated PPG (a), PGG (b), GPG (c) and $N$-benzyl GPG (d).

(a)

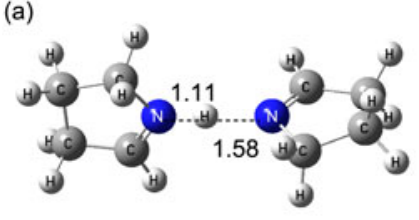

(d)
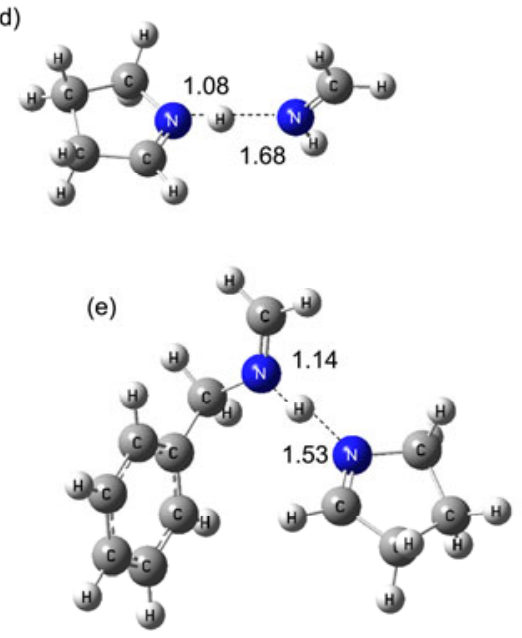

(b)

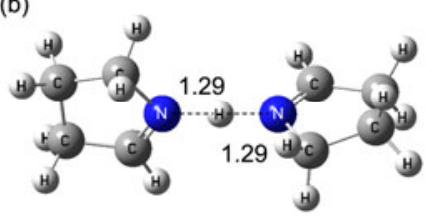

(c)

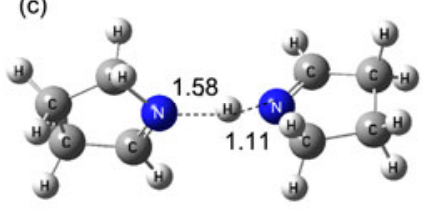

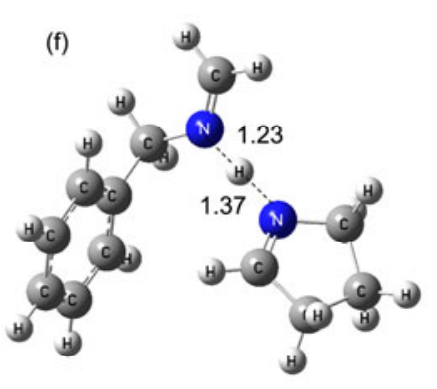

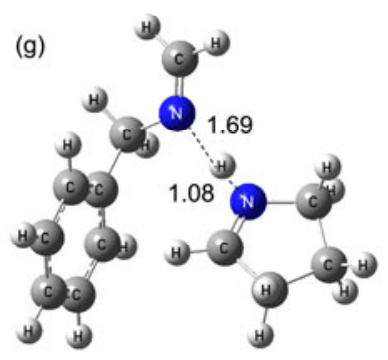

Figure 9 Optimized structures of INC_A (a), PBC_TS (b) and INC_B (c) from PPG; INC_A from PPG or INC_B from GPG (d); INC_A (e), PBC_TS (f) and INC_B (g) from $N$-benzyl GPG. 
first glycyl residue, an observable intramolecular proton transfer reaction should occur (Figure 7(c)). This should produce two distinguishable product ions at $\mathrm{m} / \mathrm{z}, 70$ and 30 . However, the calculation results (Figure 8(c)) only yielded one optimized INC for protonation, which was more favored at the imine of the second prolyl residue than that of the first glycyl residue. In addition, there was no peak at $\mathrm{m} / \mathrm{z}$ 30 in the spectrum of GPG because its mass was outside the mass range of the instrument. To address this limitation, the derivative of GPG, $N$-benzyl GPG, was studied to prove the existence of the intramolecular proton transfer reaction in GPG. Figure 7(d) shows the proposed fragmentation mechanism of the $\mathrm{a}_{2}$ ion from $N$-benzyl GPG. The reaction profile (Figure 8(d)) supported the proposed mechanisms and showed the likelihood of INC_A, PBC_TS, and INC_B. PBC_TS existing was slightly lower than that of INC_A but higher than that of INC_B. This was reflected in the relative corrected ZPEs by 0.57 and $0.18 \mathrm{kcal} \mathrm{mol}^{-1}$, which indicates that a very rapid transition occurs between the INC_A and INC_B valleys.

Based on this calculation result, we speculated that in previous GPG's calculations, INC_A had a much higher in corrected ZPE relative to PBC_TS and INC_B, which was why INC_A was unstable in the intramolecular proton transfer reaction and rapidly generated to INC_B via PBC_TS and rarely directly separated to $\mathrm{a}_{1}$ ions. This fragmentation pathway is similar to the $a_{1}-y_{x}$ pathway in the dissociation of the N-terminal [amino acid(1)-amino acid(2)] amide bonds of underivatized protonated peptides proposed by Paizs et al. [58,59]. This fragmentation pathway also agrees with the results of Harrison et al. [60]. In the $a_{1}-y_{x}$ pathway, the ratio of the abundances of the $\mathrm{a}_{1}$ and $\mathrm{y}_{x}$ ions determined by the relative PA of the two monomers can be approximated using a linear free-energy relationship [58,59] (eq. (1)):

$$
\ln \left(\frac{\mathrm{a}_{1}}{\mathrm{y}_{x}}\right) \approx\left(\frac{\mathrm{PA}_{\mathrm{N} \text {-term }}-\mathrm{PA}_{\mathrm{C} \text {-term }}}{\mathrm{RT}_{\mathrm{eff}}}\right) .
$$

This indicates that competitive proton transfer exists between the two complexes. The proton transfer between the two INCs may also be competitive in PPG, GPG, and
$N$-benzyl GPG. The relative PAs of the two residues influence the abundances of the $\mathrm{a}_{1}$ and internal $\mathrm{RCH}=\mathrm{NH}_{2}^{+}$ions. The PA of the imine of the first glycyl residue is considerably smaller than that of the second prolyl residue, and it is possible to infer that the $\mathrm{a}_{1}$ ion $(\mathrm{m} / \mathrm{z}, 30)$ should be much less abundant than the $\mathrm{RCH}=\mathrm{NH}_{2}^{+}(\mathrm{m} / z, 70)$ in $\mathrm{GPG}$.

Important experimental evidence was obtained for the existence of the intermediates for $N$-benzyl GPG. If the intermediate is to survive collisional activation, it should have an $m / z$ of 189 . In the present study, a distinct fragment ion observed in the product-ion spectrum of $\mathrm{a}_{2}$ (Figure 10) occurred at this $m / z$. The competitive intramolecular proton transfer reaction between the INCs via the PBC yielded two different product ions: an $\mathrm{a}_{1}$ ion at $\mathrm{m} / \mathrm{z}, 120$ and an internal immoniun ion at $\mathrm{m} / \mathrm{z}$ 70. However, the abundance of the former was higher than that of the latter, which had a PA value that was $2.84 \mathrm{kcal} \mathrm{mol}^{-1}$ lower (in terms of $\Delta H_{0}^{\circ}$, Table S3). This is because part of the $a_{1}$ ion may be directly generated from $\mathrm{a}_{2}$ ions cleaved at the $\mathrm{OC}-\mathrm{C}$ bond bypassing the formation of the INC. The results from the study of the fragmentation of the $\mathrm{a}_{2}$ ion from $\mathrm{N}$-benzyl GPG proved that competitive intramolecular proton transfer reactions occurred between the INCs. The main characteristics of this pathway can be used to explain most of the corresponding experimental results obtained for the protonated tripeptides and small peptides.

\section{Conclusions}

In the present research, the dissociation chemistry of primary fragment ions from protonated proline-containing tripeptides was discussed and the formation and fragmentation of the $\mathrm{a}_{2}$ ion were investigated. Calculations showed the structures of the $a_{2}$ ions generated from $b_{2}$ were cyclic and much lower in energy than the linear form. This agreed with results from earlier studies about this novel $\mathrm{a}_{2}$ ion structure. The prolyl residue in the structure had a significant effect on the energy hypersurface of the reaction by stabilizing the structure and lowering the energy. Fragmentations of the $a_{2}$ ions from GPG and PPG produced both the $\mathrm{a}_{1}$ and internal

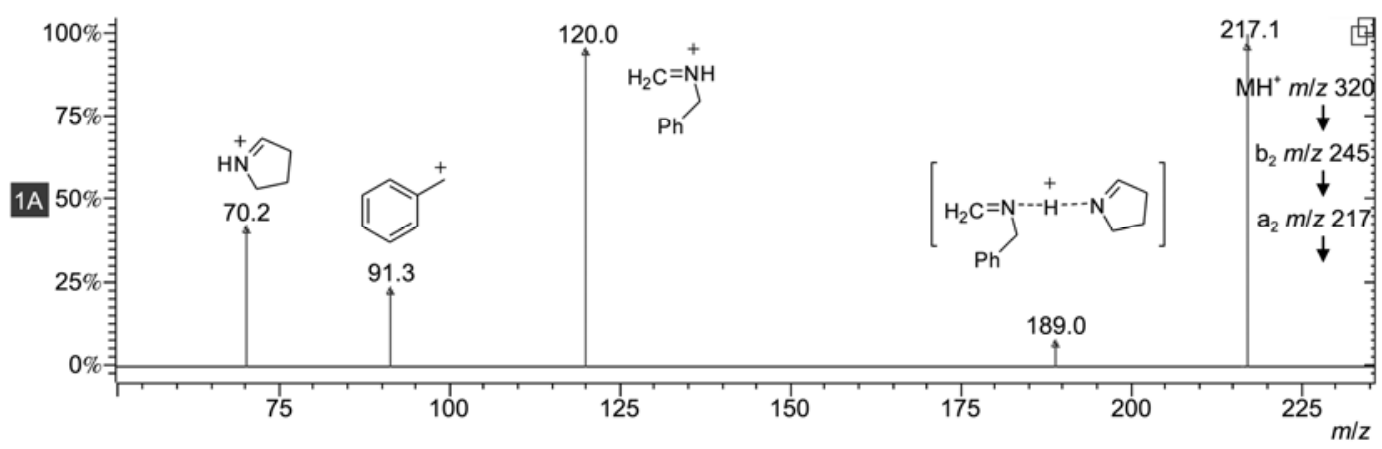

Figure 10 CID mass spectrum of the $\mathrm{a}_{2}$ ion from protonated $N$-benzyl GPG. 
$\mathrm{RCH}=\mathrm{NH}_{2}^{+}$ions. By contrast, only the $\mathrm{a}_{1}$ ion was produced from PGG. In GPG and PPG, the dissociation chemistry of $\mathrm{a}_{2}$ ions can be described by intramolecular proton transfer from the first INC produced to another INC via a PBC. The second INC then dissociates to the internal $\mathrm{RCH}=\mathrm{NH}_{2}^{+}$, which is absent in PGG.

This work was supported by China National Funds for Distinguished Young scientists (21025207), the National Natural Science Foundation of China (20975092) and the Zhejiang Provincial Natural Science Foundation of China (Y4100020).

1 Aebersold R, Goodlett D R. Mass spectrometry in proteomics. Chem Rev, 2001, 101: 269-295

2 Mann M, Hendrickson R C, Pandey A. Mass spectrometry-based proteomics. Nature, 2003, 422: 6928-6937

3 Savitski M M, Kjeldsen F, Nielsen M L, et al. Backbone carbonyl group basicities are related to gas-phase fragmentation of peptides and protein folding. Angew Chem Int Ed, 2007, 46: 1481-1484

4 Mueller M Q, Dreiocker F, Ihling C H, et al. Fragmentation behavior of a thiourea-based reagent for protein structure analysis by collisioninduced dissociative chemical cross-linking. J Mass Spectrom, 2010, 45: 880-891

5 Fenn J B, Mann M, Meng C K, et al. Electrospray ionization for mass-spectrometry. Science, 1989, 246: 64-71

$6 \mathrm{He} \mathrm{W}$, Zheng O, Yu X. Fragmentation during nanoelectrospray ionization. Anal Chem, 2010, 82: 6534-6541

7 Chen S Y. Cloning and characterization of fragments related to proline synthesis and their effect on host cells. Chin Sci Bull, 1988, 33: 878

8 Karas M, Hillenkamp F. Laser desorption ionization of proteins with molecular masses exceeding 10,000 daltons. Anal Chem, 1988, 60: 2299-2301

9 Chiappetta G, NDiaye S, Demey E, et al. Dansyl-peptides matrixassisted laser desorption/ionization mass spectrometric (MALDI-MS) and tandem mass spectrometric (MS/MS) features improve the liquid chromatography/MALDI-MS/MS analysis of the proteome. Rapid Commun Mass Spectrom, 2010, 24: 3021-3032

10 Rodriquez C F, Cunje A, Shoeib T, et al. Proton migration and tautomerism in protonated triglycine. J Am Chem Soc, 2001, 123: 30063012

11 Grewal R N, El Aribi H, Harrison A G, et al. Fragmentation of protonated tripeptides: The proline effect revisited. J Phys Chem B, 2004, 108: 4899-4908

12 Bythell B J, Csonka I P, Suhai S, et al. Gas-phase structure and fragmentation pathways of singly protonated peptides with $\mathrm{N}$-terminal arginine. J Phys Chem B, 2010, 114: 15092-15105

13 Simon E S, Papoulias P G, Andrews P C. Gas-phase fragmentation characteristics of benzyl-aminated lysyl-containing tryptic peptides. J Am Soc Mass Spectrom, 2010, 21: 1624-1632

14 Sun F, Liu R, Zong W, et al. Unique approach to the mobile proton model: Influence of charge distribution on peptide fragmentation. J Phys Chem B, 2010, 114: 6350-6353

15 Bythell B J, Suhai S, Somogyi A, et al. Proton-driven amide bondcleavage pathways of gas-phase peptide ions lacking mobile protons. J Am Chem Soc, 2009, 131: 14057-14065

16 Falick A M, Hines W M, Medzihradszky K F, et al. Low-mass ions produced from peptides by high-energy collision-induced dissociation in tandem mass spectrometry. J Am Soc Mass Spectrom, 1993, 4: 882893

17 Papayannopoulos I A. The interpretation of collision-induced dissociation tandem mass spectra of peptides. Mass Spectrom Rev, 1995, 14: 49-73

18 Biemann K, Martin S. Mass spectrometric determination of the amino acid sequence of peptides and proteins. Mass Spectrom Rev, 1987,
6: $1-76$

19 O'Hair R A J. The role of nucleophile-electrophile interactions in the unimolecular and bimolecular gas-phase ion chemistry of peptides and related systems. J Mass Spectrom, 2000, 35: 1377-1381

20 Schlosser A, Lehmann W D. Five-membered ring formation in unimolecular reactions of peptides-a key structural element controlling low-energy collision-induced dissociation of peptides. J Mass Spectrom, 2000, 35: 1382-1390

21 Polce M J, Ren D, Wesdemiotis C. Dissociation of the peptide bond in protonated peptides. J Mass Spectrom, 2000, 35: 1391-1398

22 Wysocki V H, Tsaprailis G, Smith L L, et al. Mobile and localized protons a framework for understanding peptide dissociation. J Mass Spectrom, 2000, 35: 1399-1406

23 Paizs B, Suhai S. Fragmentation pathways of protonated peptides. Mass Spectrom Rev, 2005, 24: 508-548

24 El Aribi H, Rodriquez C F, Almeida D R P, et al. Elucidation of fragmentation mechanisms of protonated peptide ions and their products: A case study on glycylglycylglycine using density functional theory and threshold collision-induced dissociation. J Am Chem Soc, 2003, 125: 9229-9236

25 El Aribi H, Orlova G, Rodriquez C F, et al. Fragmentation mechanisms of product ions from protonated tripeptides. J Phys Chem B, 2004, 108: 18743-18749

26 Verkerk U H, Siu C K, Steill J D, et al. a $a_{2}$ ion derived from triglycine: An $N_{1}$-protonated 4-imidazolidinone. J Phys Chem Lett, 2010, 1: $868-872$

27 Morton T H. Gas phase analogues of solvolysis reactions. Tetrahedron, 1982, 38: 3195-3243

28 McAdoo D. Ion-neutral complexes in unimolecular decompositions. J Mass Spectrom Rev, 1988, 7: 363-393

29 Bowen R D. Ion-neutral complexes. Acc Chem Res, 1991, 24: 364371

30 Morton $\mathrm{T} \mathrm{H}$. The reorientation criterion and positive ion-neutral complexes. Org Mass Spectrom, 1992, 27: 353-368

31 Longevialle P. Ion-neutral complexes in the unimolecular reactivity of organic cations in the gas phase. Mass Spectrom Rev, 1992, 11: 157-192

32 McAdoo D J, Morton T H. Gas-phase analogues of cage effects. Acc Chem Res, 1993, 26: 295-302

33 Liu $\mathrm{P}, \mathrm{Hu} \mathrm{N}$, Pan $\mathrm{Y}$, et al. Ion-neutral complexes resulting from dissociative protonation: Fragmentation of $\alpha$-furanylmethyl benzyl ethers and 4-N,N-dimethylbenzyl benzyl ethers. J Am Soc Mass Spectrom, 2010, 21: 626-634

34 Tu Y P, He L, Fitch W, et al. Solvation in electrospray mass spectrometry: Effects on the reaction kinetics of fragmentation mediated by ion-neutral complexes. J Org Chem, 2005, 70: 5111-5118

35 Chai Y, Jiang K, Pan Y. Hydride transfer reactions via ion-neutral complex: Fragmentation of protonated $\mathrm{N}$-benzylpiperidines and protonated $N$-benzylpiperazines in mass spectrometry. J Mass Spectrom, 2010, 45: 496-503

36 Guo C, Wan J, Hu N, et al. An experimental and computational investigation on the fragmentation behavior of enaminones in electrospray ionization mass spectrometry. J Mass Spectrom, 2010, 45: 1291-1298

$37 \mathrm{Hu}$ N, Tu Y P, Jiang K, et al. Intramolecular charge transfer in the gas phase: Fragmentation of protonated sulfonamides in mass spectrometry. J Org Chem, 2010, 75: 4244-4250

$38 \mathrm{Tu}$ Y P, Huang Y, Atsriku C, et al. Intramolecular transacylation: Fragmentation of protonated molecules via ion-neutral complexes in mass spectrometry. Rapid Commun Mass Spectrom, 2009, 23: 19701976

39 Crestoni M E, Fornarini S, Lentini M, et al. Hydride-transfer reactions in the gas phase. 2. Anchimeric assistance in the H-transfer from 1,1-dimethylcyclopentane to alkyl cations. J Phys Chem, 1996, 100: 8285-8294

40 Harrison A G. Hydrogen interchange prior to the fragmentation of protonated molecules. Org Mass Spectrom, 1987, 22: 637-641

41 Tu Y P. Fragmentation of conjugated amides at the $\mathrm{C}-\mathrm{C}(\mathrm{O})$ bond in electrospray mass spectrometry: A proton-bound dimeric intermedi- 
ate identified by the kinetic method. Rapid Commun Mass Spectrom, 2004, 18: 1345-1351

42 Gitti R K, Lee B M, Walker J, et al. Structure of the amino-terminal core domain of the HIV-1 capsid protein. Science, 1996, 273: 231-235

43 Moriarty D F, Raleigh D P. Effects of sequential proline substitutions on amyloid formation by human amylin $20-29$. Biochemistry, 1999, 38: $1811-1818$

44 Loo J A, Edmonds C G, Smith R D. Tandem mass spectrometry of very large molecules. 2. Dissociation of multiply charged prolinecontaining proteins from electrospray ionization. Anal Chem, 1993, 65: 425-438

45 Harrison A G. The gas-phase basicities and proton affinities of amino acids and peptides. Mass Spectrom Rev, 1997, 16: 201-217

46 Frisch M J, Trucks G W, Schlegel H B, et al. Gaussian 03. Revision B.01. Pittsburgh PA: Gaussian Inc., 2003

47 Dunbar R C, Hopkinson A C, Oomens J, et al. Conformation switching in gas-phase complexes of histidine with alkaline earth ions. $\mathrm{J}$ Phys Chem B, 2009, 113: 10403-10408

48 Siu C K, Guo Y, Saminathan I S, et al. Optimization of parameters used in algorithms of ion-mobility calculation for conformational analyses. J Phys Chem B, 2010, 114: 1204-1212

49 Ke Y, Zhao J, Verkerk U H, et al. Histidine, lysine, and arginine radical cations: Isomer control via the choice of auxiliary ligand (L) in the dissociation of $\left[\mathrm{Cu}^{\mathrm{II}}(\mathrm{L})(\mathrm{amino} \text { acid })\right]^{2+}$ complexes. J Phys Chem B, 2007, 111: 14318-14328

50 Siu C K, Ke Y, Orlova G, et al. Dissociation of the $\mathrm{N}-\mathrm{C}_{\alpha}$ bond and competitive formation of the $[\mathrm{zn}-\mathrm{H}]^{*+}$ and $[\mathrm{cn}+2 \mathrm{H}]^{+}$product ions in radical peptide ions containing tyrosine and tryptophan: The influence of proton affinities on product formation. J Am Soc Mass Spectrom, 2008, 19: 1799-1807
51 Paizs B, Szlavik Z, Lendvay G, et al. Formation of $\mathrm{a}_{2}^{+}$ions of protonated peptides. An ab initio study. Rapid Commun Mass Spectrom, 2000, 14: 746-755

52 Johnson R S, Martin S A, Bienmann K. Collision induced fragmentation of $\mathrm{MH}^{+}$ions of peptides. Side chain specific fragmentation ions. Int J Mass Spectrom, 1988, 86: 137-154

53 McCormack A L, Somogyi A, Dongre A R, et al. Fragmentation of protonated peptides: Surface-induced dissociation in conjunction with a quantum mechanical approach. Anal Chem, 1993, 65: 2859-2872

54 Cox K A, Gaskell S J, Morris M, et al. Role of the site of protonation in the low-energy decompositions of gas-phase peptide ions. J Am Soc Mass Spectrom, 1996, 7: 522-531

55 Rodriquez C F, Shoeib T, Chu I K, et al. Comparison between protonation, lithiation, and argentination of 5-oxazolones: A study of a key intermediate in gas-phase peptide sequencing. J Phys Chem A, 2000, 104: 5335-5342

56 Yalcin T, Khouw C, Csizmadia I G, et al. Why are B ions stable species in peptide spectra? J Am Soc Mass Spectrom, 1995, 6: 11651174

57 Yalcin T, Csizmadia I G, Peterson M R, et al. The structure and fragmentation of $\mathrm{B}_{n}(n>3)$ ions in peptide spectra. J Am Soc Mass Spectrom, 1996, 7: 233-242

58 Paizs B, Suhai S. Theoretical study of the main fragmentation pathways for protonated glycylglycine. Rapid Commun Mass Spectrom, 2001, 15: 651-663

59 Paizs B, Schnolzer M, Warnken U, et al. Cleavage of the amide bond of protonated dipeptides. Phys Chem Chem Phys, 2004, 6: 2691-2699

60 Harrison A G, Young A B, Schnoelzer M, et al. Formation of iminium ions by fragmentation of $\mathrm{a}_{2}$ ions. Rapid Commun Mass Spectrom, 2004, 18: 1635-1640

Open Access This article is distributed under the terms of the Creative Commons Attribution License which permits any use, distribution, and reproduction in any medium, provided the original author(s) and source are credited.

\section{Supporting Information}

Table S1 Cartesian coordinates, total energies, total enthalpies, total free energies, zero point energy corrections and the number of imaginary frequencies of all structures discussed in the text

Table S2 Relative electronic and zero-point energies $\left(\Delta E_{0}\right)$, relative total energy $(\Delta E)$, relative enthalpies $\left(\Delta H_{298}^{\circ}\right)$ and free energies $\left(\Delta G_{298}^{\circ}\right)$, in kcal mol ${ }^{-1}$, for GPG-, PGG-, PPG- and $N$-benzyl GPG-derived ions

Table S3 Enthalpies $\left(H^{\circ}\right)$ and relative enthalpies $\left(\Delta H_{0}^{\circ}\right)$ for product ions and neutrals calculated by DFT method at the B3LYP/6-31++G(d,p) level

The supporting information is available online at csb.scichina.com and www.springerlink.com. The supporting materials are published as submitted, without typesetting or editing. The responsibility for scientific accuracy and content remains entirely with the authors. 